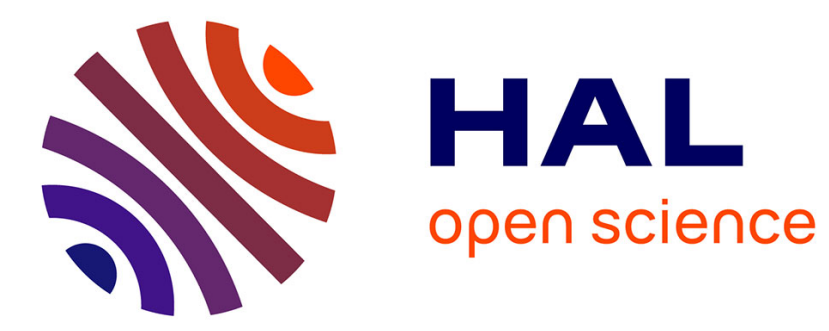

\title{
Influence of glenohumeral joint muscle insertion on moment arms using a finite element model
}

Marion Hoffmann, Mickaël Begon, Yoann Lafon, Sonia Duprey

\section{To cite this version:}

Marion Hoffmann, Mickaël Begon, Yoann Lafon, Sonia Duprey. Influence of glenohumeral joint muscle insertion on moment arms using a finite element model. Computer Methods in Biomechanics and Biomedical Engineering, 2020, 30p. 10.1080/10255842.2020.1789606 . hal-02958614

\section{HAL Id: hal-02958614 https://hal.science/hal-02958614}

Submitted on 6 Oct 2020

HAL is a multi-disciplinary open access archive for the deposit and dissemination of scientific research documents, whether they are published or not. The documents may come from teaching and research institutions in France or abroad, or from public or private research centers.
L'archive ouverte pluridisciplinaire $\mathbf{H A L}$, est destinée au dépôt et à la diffusion de documents scientifiques de niveau recherche, publiés ou non, émanant des établissements d'enseignement et de recherche français ou étrangers, des laboratoires publics ou privés. 


\title{
Influence of glenohumeral joint muscle insertion on moment arms using a finite element model
}

\author{
M. Hoffmann ${ }^{1 *}$, M. Begon ${ }^{1,2}$, Y. Lafon ${ }^{3}$, S. Duprey ${ }^{3}$ \\ ${ }^{1}$ Institute of biomedical engineering, Université de Montréal, Montréal, Canada; \\ ${ }^{2}$ School of kinesiology and physical activity sciences, Université de Montréal, Montréal, \\ Canada
}

${ }^{3}$ Laboratoire de Biomécanique et mécanique des chocs, Université Claude Bernard Lyon 1, Lyon, France, LBMC UMR_T9406

\begin{abstract}
Accurate muscle geometry is important to estimate moment arms in musculoskeletal models. Given the complex interactions between shoulder structures, we hypothesized that finite element (FE) modelling is suitable to obtain physiological muscle trajectory. A FE glenohumeral joint model was developed based on medical imaging. Moment arms were computed and compared to literature and MRI-based estimation. Our FE model produces moment arms consistent with the literature and with MRI ( $\max 17 \mathrm{~mm}$ differences). The inferior and superior fibres of a same muscle can have opposite action; predictions of moment arms are sensitive to muscle insertion (up to $20 \mathrm{~mm}$ variation).
\end{abstract}

Keywords: finite element model; shoulder; sensitivity of the footprint location; moment arms

\section{Introduction}

Musculoskeletal models can non-invasively estimate muscle and joint loadings particularly in the purpose of improving diagnosis and treatment Holzbaur et al. (2005). In so-called 1D models, muscles are defined using one or several independent lines of action. Constraints accounting for muscle unicity (no line of action of the same muscle can behave differently from the whole) are difficult to implement. For example, in 1D 
deltoid models, each part of the muscle (anterior, middle and posterior) can move freely with respect to the others while in reality the middle fibres are constrained by the anterior and posterior fibres (Webb et al. 2014). To solve such geometric issues, surface or $2 \mathrm{D}$ models were developed by adding constraints between the lines of action of a given muscle to account for muscle unicity (Hoffmann et al. 2017a). For movements with high arm elevation, shoulder 2D model provide limited accuracy (errors up to $18 \%$ on muscle length and $24 \mathrm{~mm}$ in moment arms) because the algorithm - used to compute the muscle trajectory - minimizes the distance between insertion and origin points while wrapping geometrical objects. In this case, the lines of action take the shortest path instead of taking account of muscle volume and deformation which involves a more curved trajectory (Holzbaur et al. 2007). Development of shoulder musculoskeletal models remains challenging due to the complex $3 \mathrm{D}$ arrangement of fibres that are interdependent and evolve during the movement.

Modelling shoulder muscle geometry is complex because muscles wrap over each other and over the humeral head. Furthermore, these interactions should be taken into account over a large range of motion (Haering et al. 2014). To accurately represent shoulder muscle geometry, muscle-muscle and muscle-bone interactions should be modelled. In 1D and 2D models, via-points and wrapping objects are used to represent contact with surrounding tissues and to account for such geometrical constraints. Viapoints are defined in the space and lines of action are constrained to pass by it. This modeling technique lack of realism for overhead movement (flexion or abduction over $\left.120^{\circ}\right)$ : the muscle taking a non-physiological V-shape. Similar issues can occur when using wrapping object: lines of action of a same muscle can spread on bony reliefs such as the humeral head especially during axial rotation (Marsden et al. 2008). In this condition, it is difficult to define optimal via-point positions suitable for the whole 
shoulder range of motion. It requires to know how the muscles are deforming in three dimensions.

Deformable volume models such as $3 \mathrm{D}$ finite element models seem to be a promising method to accurately represent muscle geometry. It allows the representation of structure interactions and complex representation of fibre trajectories (Blemker et al. 2005). Webb, et al. (2014) developed a finite element model limited to the rotator cuff muscles and deltoid which was only evaluated for simple motions, like axial rotation. Moreover, it requires a high computational time. The recent model of Zheng et al. (2019) includes the major structure of the shoulder complex: bones (clavicle, humerus and scapula); humeral and glenoid cartilage; rotator cuff muscles; ligaments (coracohumeral ligament, superior glenohumeral ligament, middle glenohumeral ligament and inferior glenohumeral ligament) but the authors did not a complete validation. In most cases, the model evaluation is performed by comparing moment arms to literature data. Some effort must be done to have rigorous in vivo experimental data for evaluation of the finite element results as underlined by Zheng et al. (2017).

Understanding how the estimation of muscle geometrical parameters influence the prediction of muscle function is important because many parameters as insertions area could not be easily obtain in vivo and vary widely in the literature. The locations of muscle origin and insertion points affect the predicted moment arms (Carbone et al. 2012) as well as muscle force predictions (Bolsterlee et al. 2014) because it influences the definition of the line of action. Moreover, Ackland et al. (2012) noticed a musclespecific sensibility of the moment arms on the muscle function. Therefore, a special attention must be paid to the definition of insertion and origin points, not to compromise the estimation of muscle force (Leschinger et al. 2019). 
A 3D finite element model of the rotator cuff muscles and deltoid has been constructed based on medical images. The aims of this study were (i) to compute physiological lines of action of the rotator cuff muscles and deltoid and (ii) to assess the sensibility of the moment arms to the geometry of the tendon footprint. The model prediction (in terms of moment arms and muscle lengths) will be evaluated by comparing simulation results with MRI data, the moment arms will also be assessed by comparison with literature data. We hypothesize that predictions obtained with the FE model will have reduced errors (less than $15 \%$ error on muscle length and $15 \mathrm{~mm}$ on moment arms) compared to 1D and 2D models described in Hoffmann et al. (2017b).

\section{Methods}

\subsection{FE model development}

The left shoulder bone geometry (scapula, humerus and clavicle) of a 32-year-old participant with no history of shoulder pathologies or injuries (weight: $80 \mathrm{~kg}$; height: $1.72 \mathrm{~m}$ ) was imaged in an axial mode using a CT-scan. Then, using a 3T-MRI scanner (MAGNETON Skyra, Siemens Healthcare), the same shoulder was imaged using a fast spin echo sequence to reconstruct the muscle geometry (supraspinatus SS, subscapularis SB, infraspinatus IS and deltoid DEL) (fully described in Hoffmann, et al. (2017a)). Surfaces of the muscles, tendons and bones from the MRI and CT-scan were manually segmented using the Seg3D software (Seg3D 2013). Muscle geometry from the MRI and bone geometry taken from the CT-scan images were fused together to recreate the shoulder model (Figure 1). Bones and muscles segmentation were smoothed using the 3Dslicer software (Kikinis et al. 2014). Using Scilab, the surface mesh quality was improved, and the interpenetrations were removed. The tetrahedral volume mesh was 
done with Gmsh (Geuzaine et al. 2007).
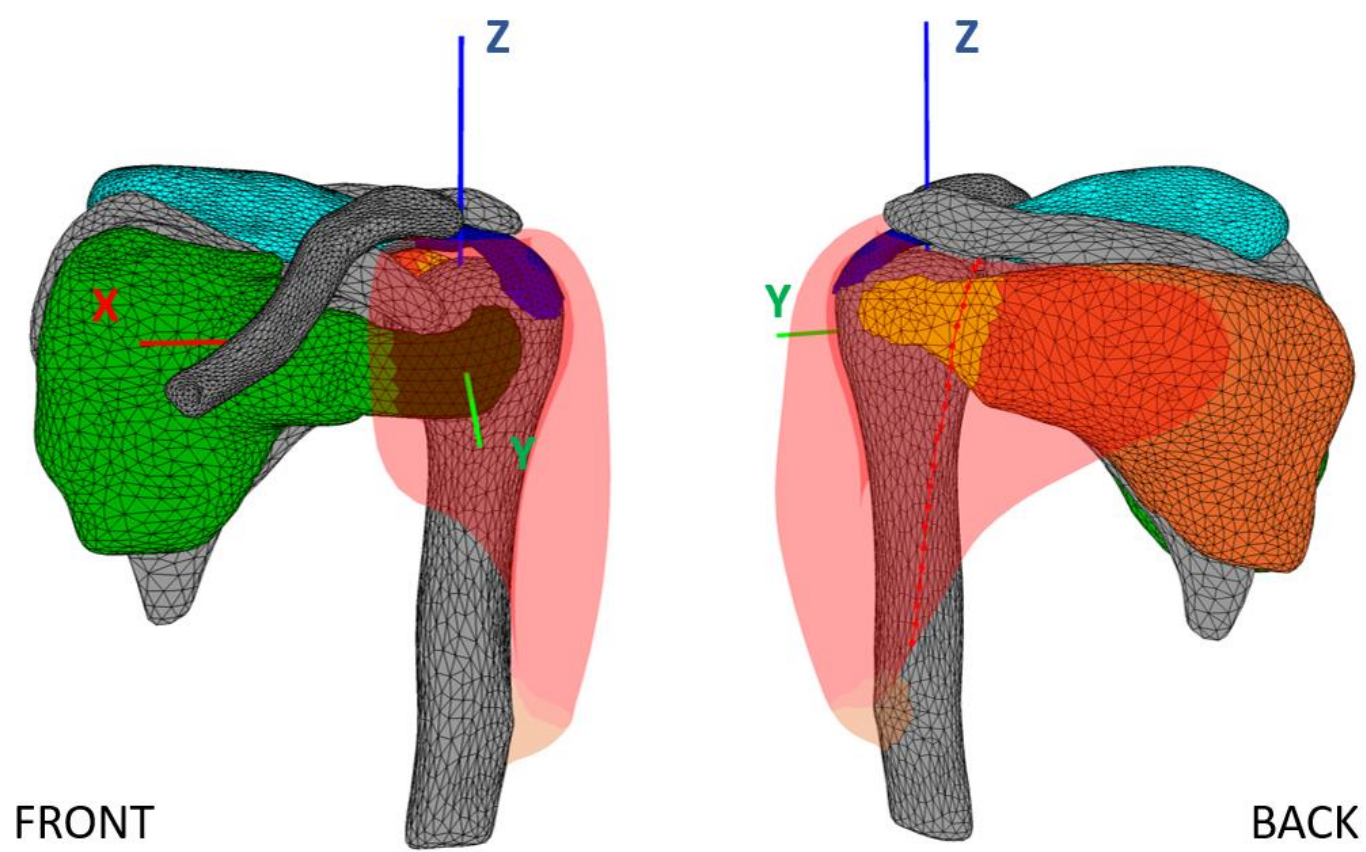

Figure 1 - The finite element model of the left shoulder: bones in grey, supraspinatus in blue, subscapularis in green, infraspinatus in yellow and deltoid in transparent red. One line of action of the deltoid is illustrated on the back view. The bones axes (here the illustration of the humerus coordinate system) were defined in accordance with the recommendations of the Internal Society of Biomechanics (Wu et al. 2005).

Muscle and tendon geometries were meshed with tetrahedron elements (Figure 1; Table 2 in Appendix). Bones were meshed with linear triangular surface elements and represented as rigid bodies as in Webb, et al. (2014). Muscles and tendons were connected to the humerus using a continuous mesh. There is also a surface mesh consisting of triangular elements to represent the fasciae of the muscles. The fascia was modelled as an elastic material (see Table 3 in Appendix for all parameters). Nodal rigid bodies were used to rigidly attach the muscles to their respective origin on the scapula or clavicle. Furthermore, a tetrahedral mesh was added between the infraspinatus and 
supraspinatus tendon to recreate the tendon fusion (Curtis et al. 2006). A mesh convergence study, done on the deltoid, showed that decreasing the element sizes by half, leads to difference of less than $0.8 \mathrm{~cm}$ for the lines of action position. Muscles were modelled using a Mooney Rivlin material law (Stelletta et al. 2016) (Table 3 in Appendix). Tendons were modelled with a linear elastic material (Itoi et al. 1995) (Table 3 in Appendix). This model only characterises the passive behaviour. Simulations with anisotropic material were performed but did not converge in large range of motion (Table 3). Thus, an isotropic material was used for soft tissues Fortunately, small discrepancies were obtained between anisotropic and isotropic simulations. Mechanical interactions were modelled with a frictionless contact model (automatic contact surface-to-surface in LS-Dyna). Penalty coefficients were assigned to mechanical contacts that may occur anatomically. This matrix was imported, and a differentiated bilateral contact pattern was created between the outer envelopes of the solids concerned (Table 4 in Appendix).

\subsection{Boundary conditions and simulations}

During the simulations, the scapula and clavicle were kept fixed. The three rotations of the humerus around the centre of the humeral head were prescribed and translations were not allowed. Simulations were performed using an explicit integration scheme in LS-DYNA (LSTC, Livermore, CA, USA). A damping global coefficient of a value of 500 was used. To validate the model according to the range of moment arm found in the literature (Hik et al. 2019), three shoulder motions were simulated: a glenohumeral abduction from $0^{\circ}$ to $120^{\circ}$ with a $3^{\circ}$ increment, flexion from $0^{\circ}$ to $60^{\circ}$ with a $2^{\circ}$ increment, and an internal-external rotation from $-45^{\circ}$ to $45^{\circ}$ with a $1.1^{\circ}$ increment. Additional movements were simulated for comparison with six additional MRI data 
from the same shoulder with a large range of motion (Hoffmann, et al. 2017a). The comparison was only done at the end of the movement to compare the postures with MRI results. Comparisons with the 1D and 2D models Hoffmann, et al. (2017b) were also performed.

\subsection{Model evaluation}

The principal lines of action of the muscle were modelled using series of lines of action passing through the middle of the muscle volume as in Marsden (2010) (17 points per line for the SS, 10 for the SB, 14 for the IS, and 21 for the DEL, see Figure 2). The initial position $P_{j}^{0}$ of the lines of action was defined in the initial mesh of each tendonmuscle unit. To calculate the position of the lines of action at a time $t_{i}$, the position of the clusters of points $P_{j}^{0}$ at time $t_{i}$ was determined according to the nodal deformation from the FE simulation. Six lines of action were used for the rotator cuff muscles and four for each of the anterior, middle and posterior parts of the deltoid. Lines of action were implemented in the same way in MRI muscle reconstruction to target moment arms and muscle lengths (see Hoffmann, et al. (2017a) for more details). Moment arms were reported according to their xyz-components namely, flexion, abduction and rotation. Moments arms were expressed as the cross product between the vector from the glenohumeral centre of rotation to the muscle first point of contact with the humeral head and a unit vector representing the direction of the line of action (mean direction of each line of action, Figure 2). The first point of contact was defined as the first point entering in contact with the wrapping object representing the humeral head when considering a line going from the origin to the insertion (Figure 2 - Representation of the lines of action for each muscle. a. Six lines of action for the subscapularis. b. The six lines of action for the infraspinatus with the illustration of the first point of contact in 
blue and the direction of the line of action (dark arrow). c. The six lines of action of the supraspinatus. $d$. The twelve lines of action of the deltoid.). The mean moment arms for each muscle was calculated (as there were six lines of action for each rotator cuff muscle and four for each part of the deltoid). The standard deviation of all the lines of action of a same muscle was reported. Muscle lengths, based on the average length of the lines of action for each muscle, were also calculated for the comparison with MRI data.

a.
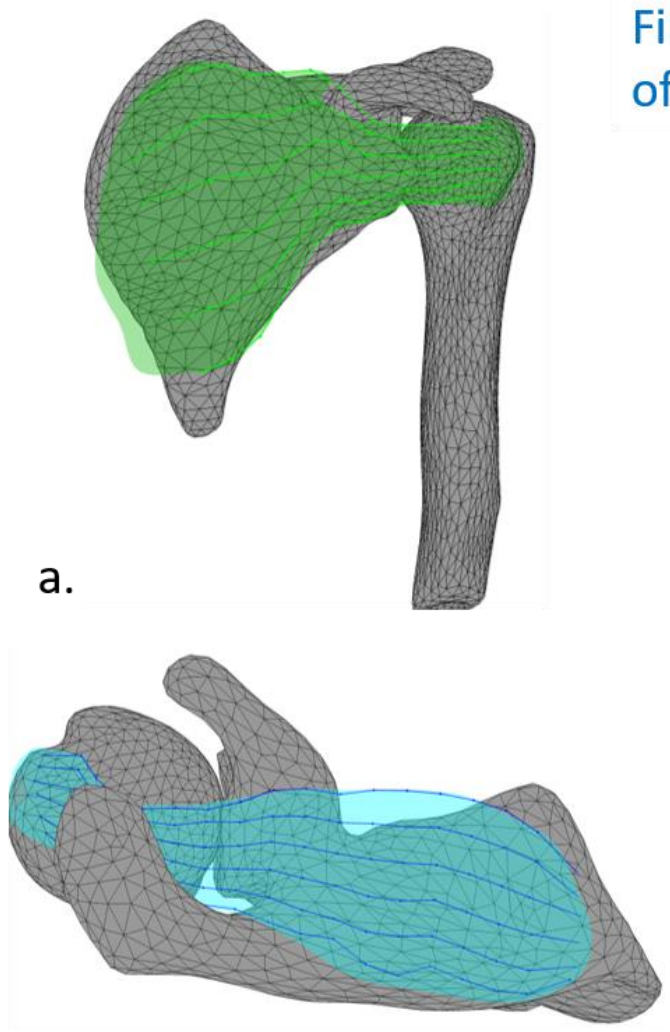

C.

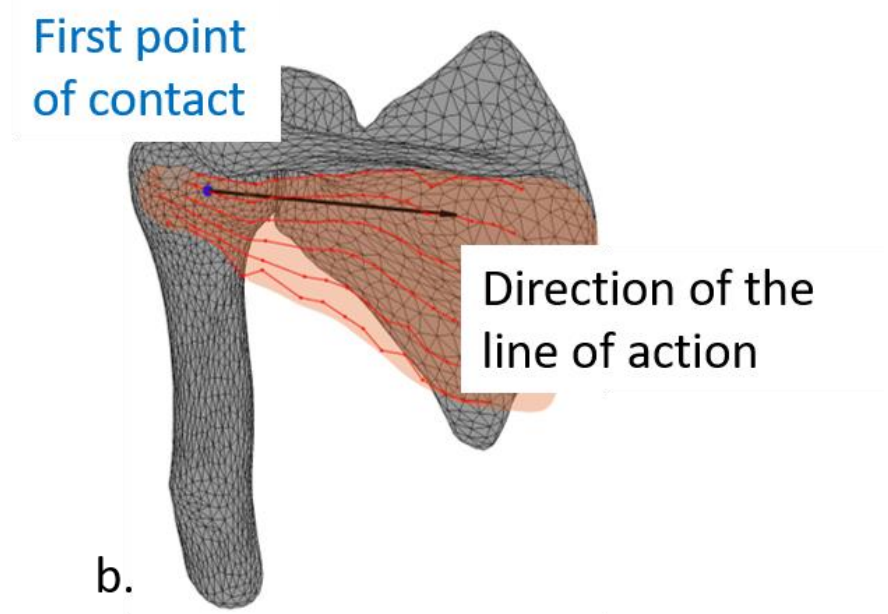

d.

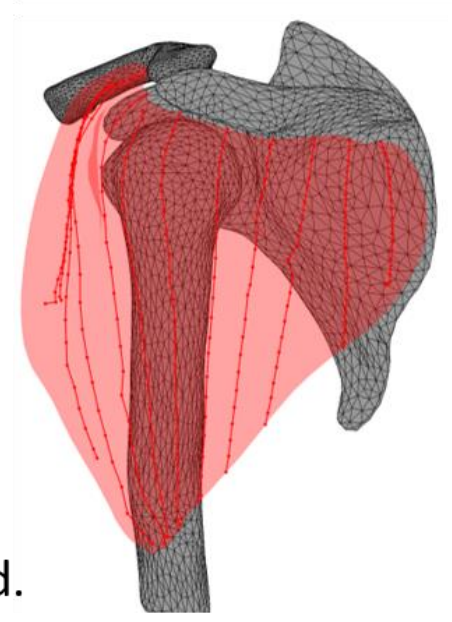

Figure 2 - Representation of the lines of action for each muscle. a. Six lines of action for the subscapularis. b. The six lines of action for the infraspinatus with the illustration of the first point of contact in blue and the direction of the line of action (dark arrow). c. The six lines of action of the supraspinatus. $d$. The twelve lines of action of the deltoid. 
To assess the sensibility of the FE model to muscle insertion on the humerus, insertion areas were shifted by approximately $10 \mathrm{~mm}( \pm$ element size $)$ from their initial position in the upward/downward (Z-axis) and medial/lateral (X-axis) direction according to the local system of coordinate of the humerus. This magnitude for sensibility analysis was chosen in agreement with Carbone, et al. (2012) for the lower extremity, and corresponds to the requirement of surgery related to supraspinatus tendon, for which the tendon footprint could be shifted medially up to $10 \mathrm{~mm}$ (Yamamoto et al. 2007). To model this shift, the geometry of the tendon and muscle were adapted to fit the new insertion positions, and then the tendon nodes were reattached to the humerus surface (new insertion areas are shown in Figure 4). Some initial interpenetration could be accepted when nodes placed on the triangles are not coincident with the underlying nodes. Each muscle-tendon unit was moved separately except for the infraspinatus and supraspinatus which were moved together because of fusion between their tendons. Twelve simulations were performed for the sensibility analysis (3 groups of muscles $\mathrm{x} 4$ directions) for each movement (abduction, flexion and rotation) and moment arms were reported.

\section{Results}

\subsection{Model assessment}

The variations and range of moment arms obtained with the FE model matches those from the literature review (Hik, et al. 2019), except for the middle deltoid fibres when performing abduction (Figure 3 for abduction and Figure 5 and Figure 6 in supplementary material for flexion and rotation). Comparisons with the same geometry for 1D and 2D models (Hoffmann, et al. 2017b) are available in Table 5 in 
supplementary material.

Abduction moment arms of the infraspinatus varied from $-14.8 \mathrm{~mm}$ (adduction) to $12.7 \mathrm{~mm}$ (abduction) at neutral position $\left(0^{\circ}\right.$ abduction) and from $4.8 \mathrm{~mm}$ to $-18.4 \mathrm{~mm}$ at $120^{\circ}$ abduction. The average standard deviation for the abduction moment arms of the subscapularis was $10.7 \mathrm{~mm}$. In the literature, moment arms of the subscapularis indicate adduction while our model shows both functions: adduction (inferior fibres) and abduction (superior fibres). The moment arms of the supraspinatus varied the least with an average standard deviation of $4.7 \mathrm{~mm}$ during the movement.
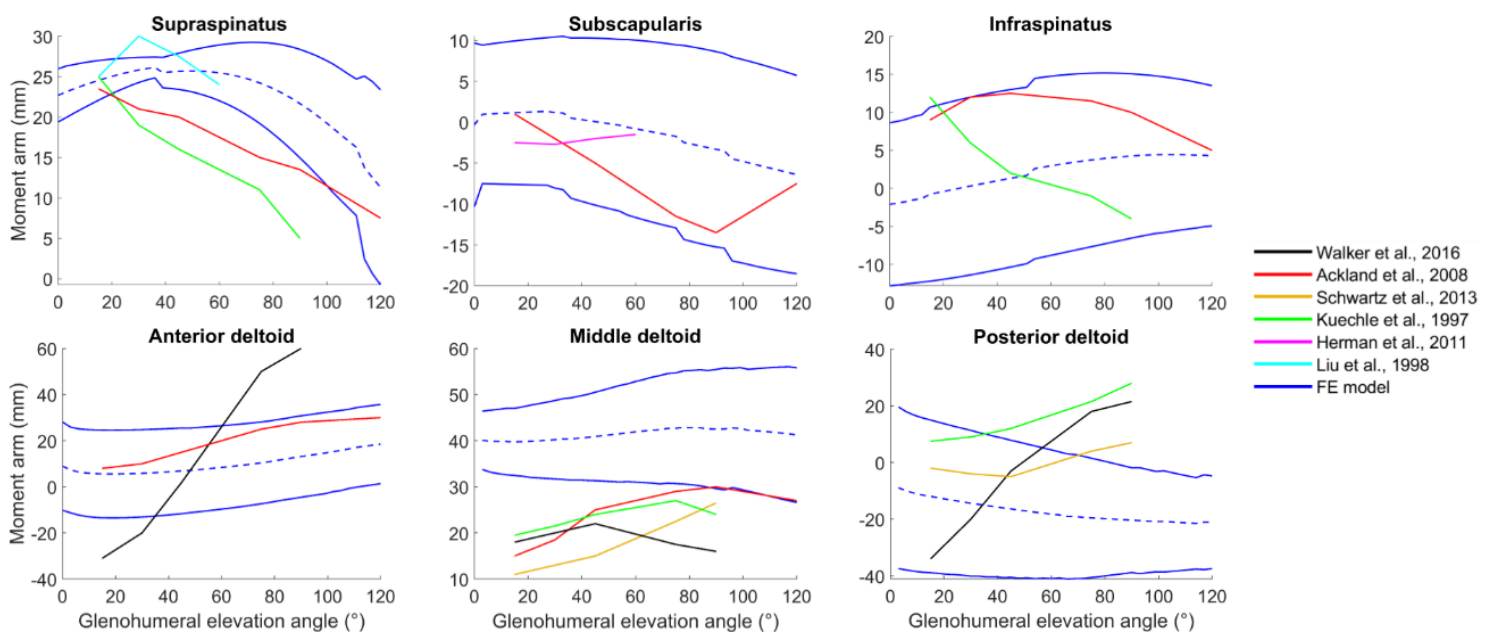

Figure 3 - Average moment arms in abduction from various studies (Hik, et al. 2019) and the mean (blue dashed line) and the standard deviation (blue line) from the model (Ackland et al. 2008a, Herrmann et al. 2011a, Kuechle et al. 1997a, Liu et al. 1997a, Schwartz, Kang, Lynch, Edwards, Nuber, Zhang, Saltzman, et al. 2013, Walker, Struk, Matsuki, Wright, Banks, et al. 2016).

When compared with the lines of action obtained from the MRI data (Table 1), a maximum error of $31 \mathrm{~mm}$ for moment arms and $14.9 \%$ for muscle lengths was observed, except for the configurations higher than $90^{\circ}$ in abduction where the errors were up to $36.5 \mathrm{~mm}$ for the moment arms and $33.4 \%$ for muscle lengths. The highest errors were observed on flexion moment arms especially for the deltoid. 
Table 1 - Mean errors muscle length (\%) and moment arm (mm) of the FE model relative to the MRI model for the anatomical position and 5 other configurations for the supraspinatus (SS), subscapularis (SB), infraspinatus (IS) and deltoid (DEL). The error was calculated as the difference between the moment arm predicted by the model and the one calculated according to the MRI (which is defined as the reference) divided by the latter. Values in red were conditions where the hypothesis was not respected

\begin{tabular}{|c|c|c|c|c|c|c|c|c|c|c|c|c|c|c|c|c|}
\hline \multirow[t]{2}{*}{ Positions } & \multicolumn{4}{|c|}{$\begin{array}{c}\text { Error in muscle LENGTH } \\
(\%)\end{array}$} & \multicolumn{4}{|c|}{$\begin{array}{l}\text { Errors in FLEXION } \\
\text { moment arm (mm) }\end{array}$} & \multicolumn{4}{|c|}{$\begin{array}{c}\text { Errors in ABDUCTION } \\
\text { moment arm (mm) }\end{array}$} & \multicolumn{4}{|c|}{$\begin{array}{l}\text { Errors in ROTATION } \\
\text { moment arm (mm) }\end{array}$} \\
\hline & SS & SB & IS & DEL & SS & SB & IS & DEL & SS & SB & IS & DEL & SS & SB & IS & DEL \\
\hline Anatomical & 5.1 & -0.4 & 2.9 & 2.5 & 0.4 & -0.05 & -2.6 & -5.1 & -4.0 & -6.9 & -4.6 & 1.5 & -5.9 & 3.8 & 0.5 & 0.2 \\
\hline Internal rotation (IR) & 14.9 & 3.1 & 3.2 & 4.1 & 5.1 & 7.6 & 3.2 & 4.8 & -3.3 & -7.4 & -10.2 & 1.9 & 1.9 & 3.3 & 1.6 & -0.1 \\
\hline External rotation (ER) & 5.5 & 1.9 & -2.9 & 2.7 & -4.6 & -4.1 & -2.4 & -3.8 & -4.3 & -6.8 & -3.9 & -1.4 & 2.9 & 2.9 & 1.2 & 0.1 \\
\hline $90^{\circ}$ abduction + IR & 13.2 & -3.9 & 4.5 & -6.4 & -1.0 & -0.3 & -7.8 & -31.1 & -6.5 & 5.6 & -13.6 & -6.8 & 6.3 & 3.6 & 8.7 & 2.8 \\
\hline $90^{\circ}$ abduction + ER & 16.2 & 5.5 & 6.7 & 13.7 & 2.5 & -5.0 & -0.9 & -30.9 & -1.3 & 4.3 & -12.0 & -18.2 & -1.5 & 1.3 & 12.6 & 2.6 \\
\hline Full abduction + ER & 33.4 & 7.1 & 20.4 & 19.8 & -1.3 & -5.9 & -4.8 & -36.5 & -0.1 & -3.6 & -9.3 & -1.9 & 5.7 & 1.0 & 1.4 & 2.1 \\
\hline Mean & 14.7 & 3.6 & 5.8 & 6.1 & -0.2 & -1.3 & -2.6 & -17.1 & -3.3 & -2.5 & -8.9 & -4.2 & 1.6 & 2.6 & 4.3 & 1.3 \\
\hline
\end{tabular}




\subsection{Model sensitivity to muscle insertion}

Average moment arms in abduction varied substantially (differences up to $19.3 \mathrm{~mm}$ on subscapularis moment arm) within a muscle when insertions were moved (Figure 4 for abduction and Figure 7 and Figure 8 in supplementary material for flexion and rotation). On average, the shape of the curves remained the same between insertion configurations, but the values of the moment arms changed. Average moment arms in abduction for the subscapularis varied from $8.7 \mathrm{~mm}$ (upward in red) to $-11.8 \mathrm{~mm}$ (downward in green) at neutral position and from $-6.1 \mathrm{~mm}$ (upward in red) to $-10.6 \mathrm{~mm}$ (downward in green) at $120^{\circ}$ abduction. These differences could lead to abduction or adduction muscle function according to the insertion area. Differences between moment arms up to $18 \mathrm{~mm}$ were observed in the infraspinatus. 

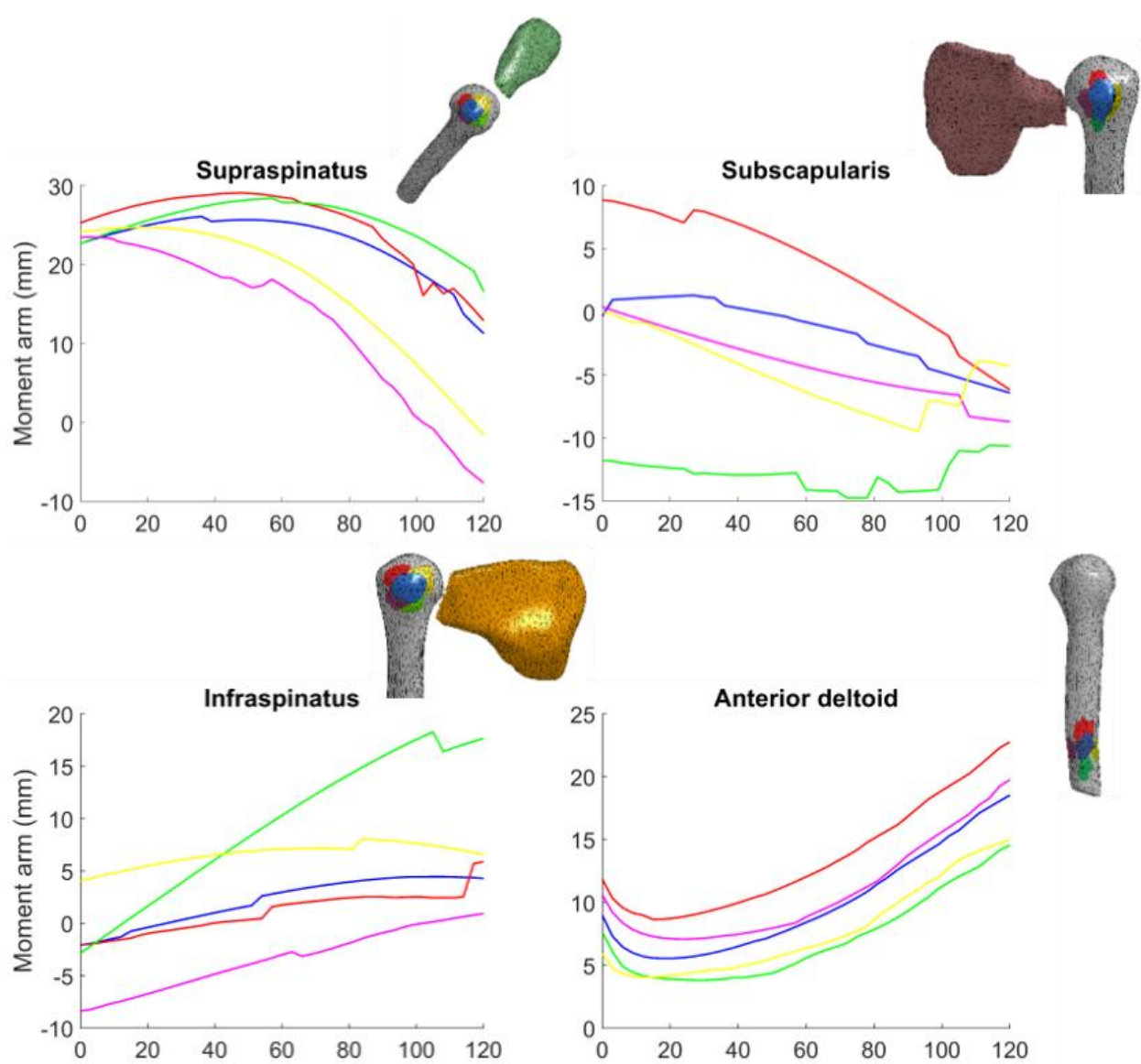

Anterior deltoid
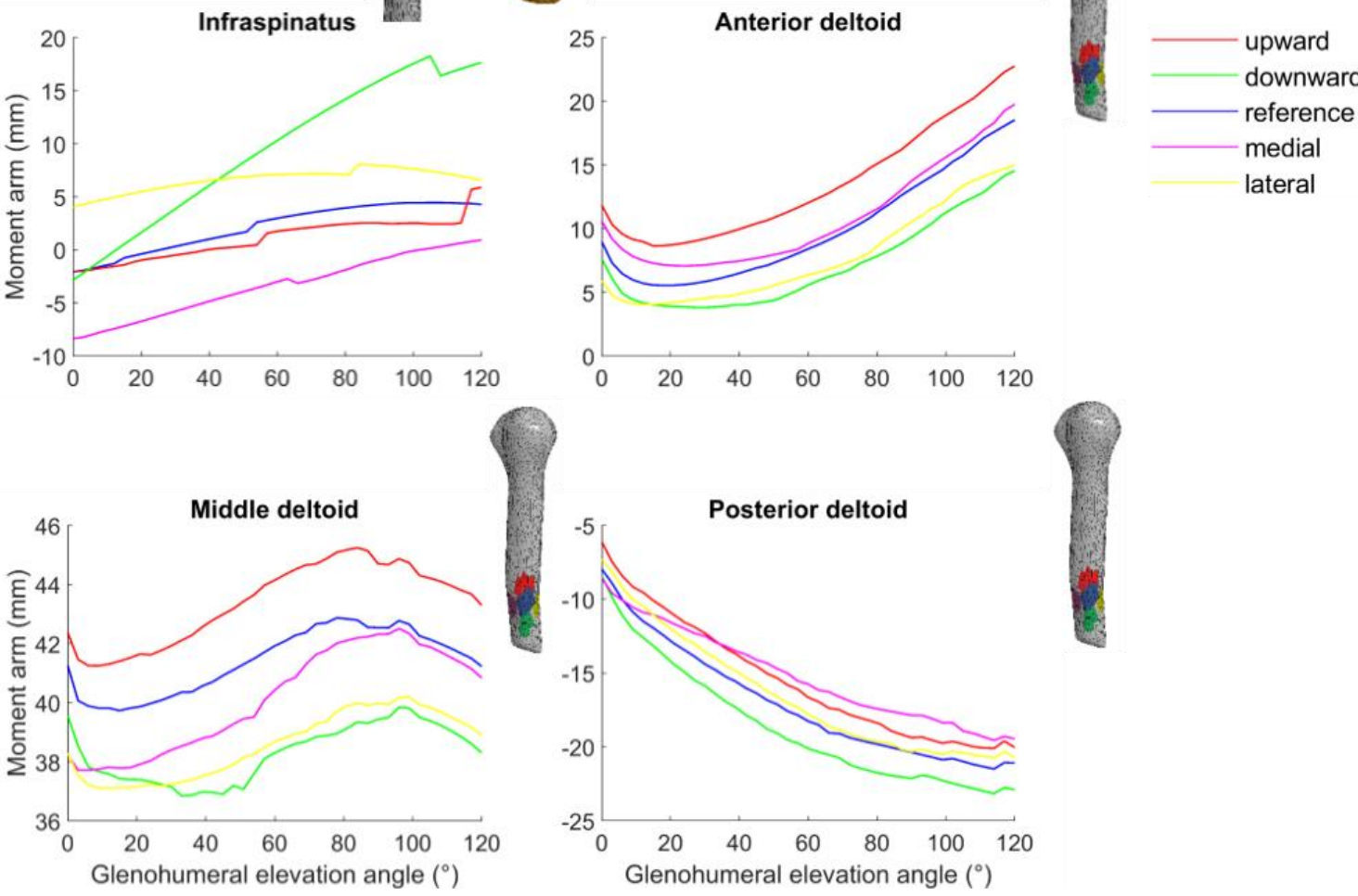

Figure 4 - Mean $(n=6$ lines of action for the rotator cuff muscle; $n=4$ for each part of the deltoid) moment arms in abduction for the 5 positions (reference in blue, $10 \mathrm{~mm}$ upward in red, downward in green, medial in purple and lateral in yellow) of the footprint area for each muscle and the corresponding illustration of insertion area for each muscle. 


\section{Discussion}

A 3D FE model of the rotator cuff muscle and deltoid was developed to accurately (in a range of error of $15 \%$ for muscle length and $15 \mathrm{~mm}$ for moment arms) predict muscles geometry (length and moment arms) by accounting for muscle volume conservation and muscle interaction with surrounding tissues, while taking into account the variability of the tendon footprint location on the humeral head. The main findings of our study are that (i) our model produces moment arm variations that are consistent with the results from the literature (Hik, et al. 2019); (ii) our model predicted higher variability in moment arms across fibres within each muscle than in 1D musculoskeletal models where muscles are often represented with few lines of action (Quental et al. 2015); (iii) changing muscle insertion of $10 \mathrm{~mm}$ could lead to a prediction of antagonist function of the lines of action. Our hypothesis is respected except for the moment arms in flexion for the deltoid in three configurations and for the muscle length of movement with high amplitude of movement.

The moment arms standard deviation showed a high variability between each lines of action moment arms with a maximal value of $27.5 \mathrm{~mm}$. Our FE model showed more variability in moment arms within a muscle compared to the representations with one line of action from the literature. This reinforces the recommendation of Quental, et al. (2015) about the need for several $(\geq 6)$ lines of action to represent each rotator cuff muscle (same number of lines actions used as in Nikooyan et al. (2011)). Furthermore, simulations were conducted on a higher abduction range of motion than usual. The maximum amplitude of movement was restrained to $120^{\circ}$ of glenohumeral abduction which corresponds to $180^{\circ}$ of thoracohumeral elevation considering a scapulohumeral rhythm of 2:1. These ranges of motion were in accordance with cadaveric studies (Hik, et al. 2019) and were higher than the ones tested using other FE models (Webb, et al. 
2014). Therefore, our finite element model seems to be a good tool for estimating the moment arms over a large range of motion.

When compared to the literature data, results showed some differences in amplitude of moment arms. The variability could be explained by the choose of the insertion area and the muscle fibres considered: differences in moment arms with the literature was up to $22.3 \mathrm{~mm}$ but sensibility study also showed variations up to $18 \mathrm{~mm}$. In general, differences between our results and experimental data could be explained by the use of different measurement techniques to compute moment arms between our study (geometric method) and the literature (tendon excursion performed on cadaveric subject). Indeed, an average difference of $7.2 \mathrm{~mm}$ was found by Hughes et al. (1997) for the infraspinatus moment arm in abduction between the geometric method and the tendon excursion method. Moreover, there are some differences between in vivo volunteer movement and in vitro forced one, and the uncertainty on boundary conditions could lead to some divergences when compared to the literature. Despite these differences, the predictive moment arms our FE model is reliable to predict muscle fibres function as it reproduces the same behaviour as reported in the literature.

The FE model and the results found in literature data both showed that the middle deltoid fibres are abductors but not with the same amplitude: the maximum abduction moment arm for the FE model is $52.3 \mathrm{~mm}$ while the maximum from the literature data is about $30 \mathrm{~mm}$ (Hik, et al. 2019). Moment arms for the fibres of the middle deltoid are twice higher in the FE model than what could be found in the literature (Figure 3), meaning that for the same activation the muscle will generate twice the joint torque in abduction. This may also explain why, in arm abduction, the middle deltoid is not much involved when muscle activation is estimated using static optimization. However, the deltoid moment arm error in abduction between our FE 
model and MRI-based measurements in full abduction with external rotation is very small: $1.9 \mathrm{~mm}$ (last position in Table 1). Difference with the literature could be explained by the difference in the characteristics of the participants. Indeed, our FE model was developed based on the imaging of a 32-year-old healthy and active adult, whereas literature data used for the comparison came from cadaveric studies on older population that could suffer from muscle sarcopenia (average age of specimens used in the study ranges from 59 to 87-year-old). Moreover, comparison with the same geometry show less difference in moment arms with the FE model than with classic musculoskeletal model: the mean differences on moment arms for the $1 \mathrm{D}, 2 \mathrm{D}$ and $3 \mathrm{D}$ model is $6.3 \mathrm{~mm}, 4.5 \mathrm{~mm}$ and $2.6 \mathrm{~mm}$ respectively (results Table S1 in supplementary material). This reinforces the need to have more subject-specific validation data or to be able to take account of subject morphology when assessing a model because some errors are just associated with a difference in subject characteristics.

Finite element model offers the ability to consider interaction between structure which is one of the weakness of 1D and 2D musculoskeletal model. For example, the deltoid is usually represented by three independent compartments (anterior, middle and posterior parts) which are assumed to be mechanically independent, and whose paths can move freely with respect to one another. A previous study (Stelletta, et al. 2016) focusing on the lower limb did some comparison simulation between two conditions: with and without taking into account interaction between structure. The results showed that interactions between structures play an important role in the evaluation of muscle trajectories and muscle forces: errors between musculotendinous forces with and without considering interaction could be up to $34.4 \%$. Given the variability observed for the moment arms in this study, another important aspect for geometric modelling is the number of lines of action used to represent each muscle for the prediction of moment 
arms (Quental, et al. 2015). Using 6 lines of action to represent the rotator cuff muscle and 12 for the deltoid offered an appropriate representation of muscle trajectories since with this amount, each fibre could have a distinct function without adding unnecessary redundancy in the model.

Parametrization of 3D FE models is more complex than 1D and 2D models as they need more input data. Usually, the construction of 3D FE models requires specification about the spatial arrangement of fibre directions obtained using a mapping method (Kim et al. 2007). As we defined the trajectory of lines of action independently of the mesh of the muscle and because the material property used is isotropic, there is no need to have a very complex mesh following fibre directions. Furthermore, the convergence study conducted on the deltoid shows that decreasing element size by half leads to the same errors when comparing the moment arms with MRI. To provide an initialised state of the FE model, it was assumed that all areas of muscle and tendon are at zero state strain, which is a questionable assumption. For example, Elwell et al. (2018) used "strings of pearls" representation to initiate some stretches within fibres. However, the values used to pull on the springs were not based on physiological data. Future experimental measurements should be performed to assess the initial stretches within fibres in each muscle.

The present study has some limitations. First, although the model works well in abduction, some improvements have to be made to be able to perform simulations over the full range of motion allowed on the shoulder. The calculation convergence was difficult at high elevation angle due to high muscle deformations and the lack of initial stretches within fibres. The convergence issue could probably be solved by creating a new mesh at a certain critical angle. Including the scapula movement and allowing translation for the humerus head could also help having a better representation for 
higher elevation angles as it will imply fewer kinematics constraints. Muscles should be modelled as anisotropic, but comparison were made between both material properties for muscle and less than $1.5 \mathrm{~mm}$ differences between moment arms were observed. Finally, the FE model did not take account of muscle activation yet as in Zheng, et al. (2019) and Webb, et al. (2014). However, in these models, no validation was done of the active comportment of the models. Avoiding active comportment seems to be a good compromise between having a physiological representation of muscle trajectory and computation time (simulation took a few minutes for our model ( 1 core, single precision, Intel Xeon processor, 24 Go RAM) compared to 20h for Webb, et al. (2014)). Future work should focus on muscle activation with validation based on experimental data of muscle deformation at different levels of isometric contraction (Hoffmann et al. 2019). The muscle activation will be performed using 3D constitutive law enabling activation (Nagy et al. 2018).

The footprint location of rotator cuff muscles is particularly important in tendons transfer surgery which consists in reattaching the tendon on the bone surface. It could be employed to improve the function for patients with irreparable rotator cuff tears (Neri et al. 2009). Apreleva et al. (2002) showed that in case of surgical intervention on the rotator cuff tendon, the repairs did not restore the initial supraspinatus footprint. As seen in this study, reattaching the tendon could be challenging as a variation in tendon footprints could lead to another muscle function. Indeed, the sensitivity study performed showed differences in moment arms up to $20 \mathrm{~mm}$ for some muscles during abduction resulting in muscles becoming either abductor or adductor depending on insertion area. This study underlines the need for a better understanding of the anatomy and biomechanics as well as surgical skills (Mueller et al. 2014) to preserve shoulder integrity after surgery. Surgery could lead to a reduction of the supraspinatus moment 
arm (Leschinger, et al. 2019). More studies concerning anatomical insertion and origin area for shoulder muscles should be performed to better initialise musculoskeletal models and have a better understanding of muscle function.

Our FE model could be used in prospective simulations representing pathological conditions. For example, tears could be modelled by deleting some 3D elements in the tendon. It would help to improve the understanding of rotator cuff tears and assess the main difference between symptomatic and asymptomatic patient for tears with the same characteristics. The work of Jackson et al. (2012) and Jackson et al. (2013) could also be adapted in a 3D numerical study to evaluate optimal shoulder immobilisation postures that reduce stress, strain and mechanical coupling between muscle compartments after surgical repair of the rotator cuff tendons.

\section{Conclusion}

The 3D FE model of the glenohumeral joint predicted moment arms in accordance with the values reported in the literature. Furthermore, our model predicted higher variability in moment arms across fibres within each muscle than 1D musculoskeletal models. Our study underlined the fact that uncertainty on muscle insertion could lead to a prediction of opposite function of the lines of action (for example adduction instead of abduction). The model developed here could be used to better understand mechanisms of shoulder injuries.

\section{Acknowledgments}

The work was supported by a NSERC grant and the financial support from the Auvergne Rhônes-Alpes region (SCUSI project 2017). 


\section{Appendix}

Table 2 - Summary of the number of nodes and elements used in the finite element model

\begin{tabular}{|c|c|c|c|c|c|c|c|}
\hline & \multicolumn{3}{|c|}{ Bones } & \multicolumn{4}{|c|}{ Muscle and tendon } \\
\hline & Humerus & Scapula & Clavicle & Supraspinatus & Subscapularis & Infraspinatus & Deltoid \\
\hline Number of nodes & 1503 & 1503 & 1503 & 2926 & 2504 & 2627 & 2531 \\
\hline Number of elements & 3001 & 3000 & 3000 & 11499 & 9431 & 10346 & 9427 \\
\hline
\end{tabular}

Table 3 - Input parameters for the material properties used to represent fascia, tendon and muscle

\begin{tabular}{|c|c|c|c|c|c|}
\hline & & Mass density $\left(\mathrm{kg} / \mathrm{m}^{3}\right)$ & Poisson's ratio & Young's modulus (MPa) & $\mathrm{A}$ \\
\hline Fascia & Elastic & 1200 & 0.40 & 270000 & \\
\hline Tendon & Linear elastic & 1200 & 0.40 & 270000 & \\
\hline \multirow[t]{2}{*}{ Muscles } & Mooney Rivlin & 1200 & 0.49 & 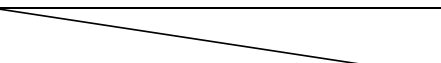 & 8 \\
\hline & & Mass density $\left(\mathrm{kg} / \mathrm{m}^{3}\right)$ & Hyperelastic coefficients & Young's modulus (MPa) & Stretch ratio \\
\hline \multirow[t]{5}{*}{ Muscles } & Transversely isotropic & 1200 & $\mathrm{C} 1=4000$ & 500000 & 1.1 \\
\hline & hyperleastic & & $\mathrm{C} 2=1000$ & & \\
\hline & & & $\mathrm{C} 3=2.09$ & & \\
\hline & & & $\mathrm{C} 4=32.2$ & & \\
\hline & & & $\mathrm{C} 5=618.2$ & & \\
\hline
\end{tabular}


Table 4 - Penalty coefficient used in the definition of contacts between surfaces

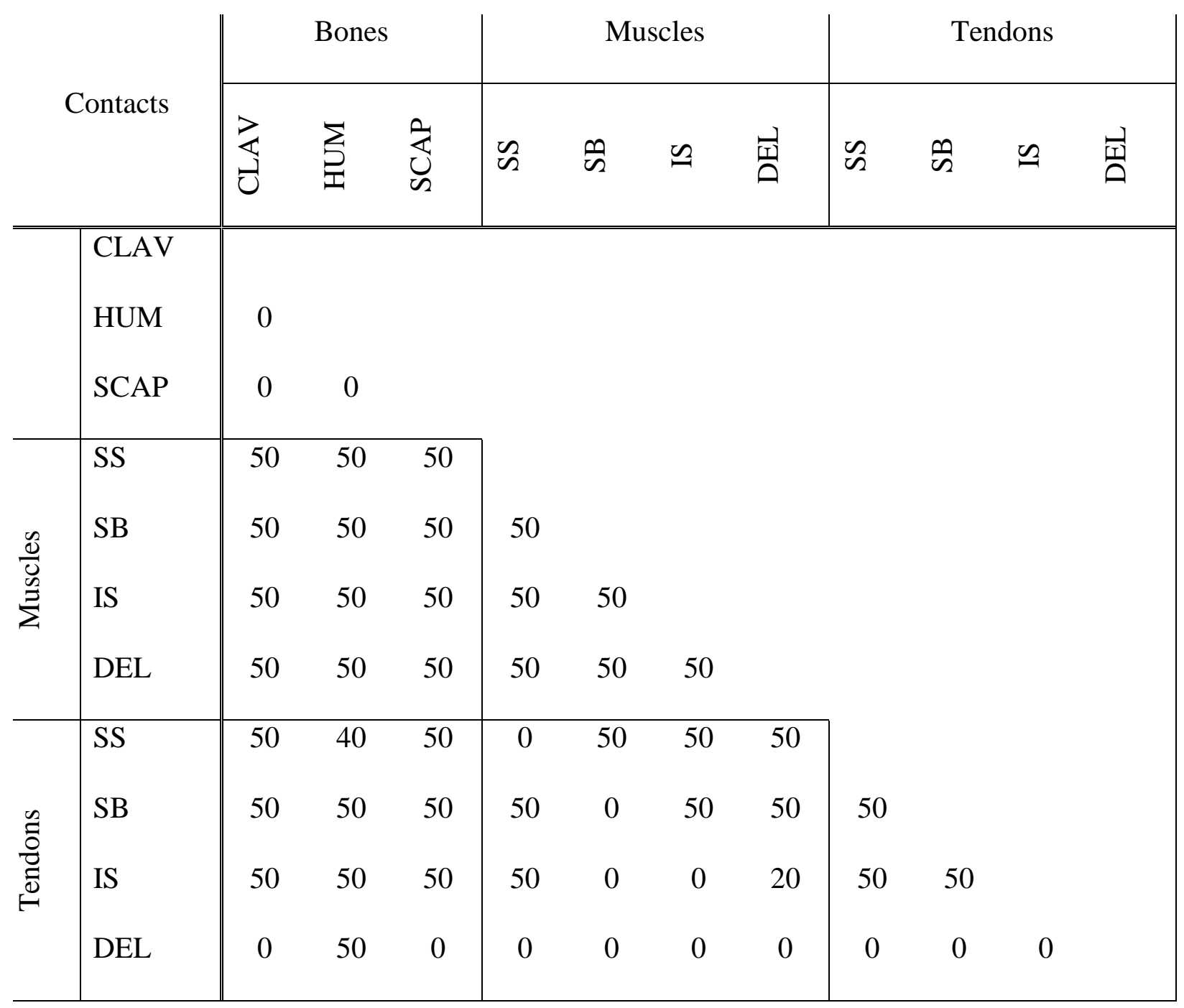


Supplementary material

Comparison between models integrating1D (line), 2D (mesh) and 3D (finite element (FE)) muscle representations.

Table 5- Mean errors muscle length (\%) and moment arm (mm) of the line and mesh models relative to the MRI model for the supraspinatus (SS), infraspinatus (IS), subscapularis (SB) and deltoid (DE).

\begin{tabular}{|c|c|c|c|c|c|c|c|c|c|c|c|c|c|c|c|c|c|}
\hline \multirow{2}{*}{ Positions } & \multirow[t]{2}{*}{ Model } & \multicolumn{4}{|c|}{ Errors in muscle LENGTH (\%) } & \multicolumn{4}{|c|}{$\begin{array}{c}\text { Errors in FLEXION moment arm } \\
(\mathrm{mm})\end{array}$} & \multicolumn{4}{|c|}{$\begin{array}{c}\text { Errors in ABDUCTION moment } \\
\text { arm (mm) }\end{array}$} & \multicolumn{4}{|c|}{$\begin{array}{c}\text { Errors in ROTATION moment } \\
\text { arm (mm) }\end{array}$} \\
\hline & & SS & IS & SB & DE & SS & IS & SB & DE & SS & IS & SB & DE & SS & IS & SB & DE \\
\hline \multirow[t]{3}{*}{ 1. Anatomical } & Line & -4.5 & -6.0 & -6.8 & 0.6 & 4.9 & 2.4 & 5.4 & 12.8 & 12.6 & -5.5 & 6.4 & 15 & 2.5 & 5.7 & -6.5 & 3.5 \\
\hline & Mesh & -4.5 & -5.8 & -5.8 & 1.9 & 5.0 & 2.5 & 6.1 & 8.0 & 12.8 & -5.6 & 7.1 & 15 & 2.8 & 5.4 & -5.4 & 2.9 \\
\hline & FE & 5.2 & 2.9 & -0.4 & 2.5 & 0.4 & -2.6 & -0.05 & -5.1 & -4.0 & -4.6 & -6.9 & 1.5 & -5.9 & 0.5 & 3.8 & 0.2 \\
\hline \multirow{3}{*}{$\begin{array}{l}\text { 2. Internal } \\
\text { rotation (IR) }\end{array}$} & Line & -6.1 & 7.0 & -8.7 & 1.9 & 1.3 & 36.1 & 8.8 & 12.5 & 11.2 & 13.6 & 5.0 & 8.7 & -5.2 & 55.6 & -11.8 & 3.9 \\
\hline & Mesh & -6.0 & -3.1 & -7.9 & 2.8 & 1.2 & 25.7 & 9.2 & 6.1 & 11.1 & -5.9 & 5.2 & 14.1 & -5.3 & 11.6 & -11.3 & 6.9 \\
\hline & FE & 14.9 & 3.2 & 3.1 & 4.1 & 5.1 & 3.2 & 7.6 & 4.8 & -3.3 & -10.2 & -7.4 & 1.9 & 1.9 & 1.6 & 3.3 & -0.1 \\
\hline \multirow{3}{*}{$\begin{array}{l}\text { 3. External } \\
\text { rotation (ER) }\end{array}$} & Line & -2.9 & -8.0 & -3.5 & 0.7 & 7.1 & 14.1 & -9.9 & 10.6 & 11.6 & -33.1 & -2.3 & 12.3 & -0.2 & 9.1 & -9.7 & 6.0 \\
\hline & Mesh & -2.8 & -7.8 & -2.5 & 2.0 & 7.0 & 14.4 & -9.2 & 9.2 & 12.0 & -33.1 & -1.7 & 10.4 & 0.1 & 9.2 & -8.7 & 6.2 \\
\hline & FE & 5.5 & -2.9 & 1.9 & 2.7 & -4.6 & -2.4 & -4.1 & -3.8 & -4.3 & -3.9 & -6.8 & -1.4 & 2.9 & 1.2 & 2.9 & 0.1 \\
\hline \multirow{3}{*}{$\begin{array}{l}\text { 4. } 90^{\circ} \text { abduction } \\
+\mathrm{IR}\end{array}$} & Line & -8.8 & -9.1 & -9.8 & -14.6 & 4.1 & 5.0 & -35.7 & 8.9 & 10.3 & 12.1 & -6.6 & 1.8 & -3.8 & 16.9 & -4.3 & 11.8 \\
\hline & Mesh & -8.5 & -8.9 & -6.5 & -14.0 & 5.7 & 4.9 & -23.7 & 14.6 & 11.1 & 11.8 & -2.9 & 3.3 & -1.6 & 16.8 & 0.1 & 10.9 \\
\hline & FE & 13.2 & 4.5 & -3.9 & -6.4 & -1.0 & -7.8 & -0.3 & -31.1 & -6.5 & -13.6 & 5.6 & -6.8 & 6.3 & 8.7 & 3.6 & 2.8 \\
\hline \multirow{3}{*}{$\begin{array}{l}5.90^{\circ} \text { abduction } \\
+\mathrm{ER}\end{array}$} & Line & -6.2 & -5.1 & -1.0 & 3.1 & 10.6 & 3.9 & 7.1 & -6.9 & 17.6 & 9.5 & -7.0 & -2.9 & 0.5 & 5.0 & -13.1 & 2.4 \\
\hline & Mesh & -6.2 & -4.8 & -0.3 & 5.2 & 10.2 & 4.1 & 5.5 & -20.8 & 17.4 & 8.2 & -7.6 & -7.3 & 0.6 & 3.9 & -11.8 & 5.2 \\
\hline & FE & 16.2 & 6.7 & 5.5 & 13.7 & 2.5 & -0.9 & -5.0 & -30.9 & -1.3 & -12.0 & 4.3 & -18.2 & -1.5 & 12.6 & 1.3 & 2.6 \\
\hline \multirow{3}{*}{$\begin{array}{l}\text { 7. Full } \\
\text { abduction + ER }\end{array}$} & Line & -17.7 & -9.7 & -9.6 & -54.1 & -18.9 & -13.3 & -4.2 & 23.0 & -9.5 & 3.7 & 16.8 & 10.0 & -18.2 & -14.4 & -42.2 & 1.7 \\
\hline & Mesh & -13.9 & -9.4 & 0.8 & -54.2 & -7.2 & -13.5 & -8.0 & 16.4 & -7.8 & 3.8 & 20.2 & 13.8 & -4.7 & -14.3 & -17.1 & 1.8 \\
\hline & FE & 33.4 & 20.4 & 7.1 & 19.8 & -1.3 & -4.8 & -5.9 & -36.5 & -0.1 & -9.3 & -3.6 & -1.9 & 5.7 & 1.4 & 1.0 & 2.1 \\
\hline \multirow[t]{3}{*}{ MEAN } & Line & -7.7 & -5.2 & -6.5 & -9.4 & 1.5 & 8.0 & -4.8 & 10.1 & 9.0 & 13.5 & 2.1 & 7.5 & -4.1 & 13.0 & 14.6 & 4.9 \\
\hline & Mesh & -6.9 & -6.6 & -3.7 & -9.4 & 3.7 & 6.4 & 4.9 & 5.6 & 9.4 & 11.7 & 3.4 & 8.2 & -1.3 & 5.4 & -9.0 & 5.7 \\
\hline & FE & 14.7 & 5.8 & 3.6 & 6.1 & -0.2 & -2.6 & -1.3 & -17.1 & -3.3 & -8.9 & -2.5 & -4.2 & 1.6 & 4.3 & 2.6 & 1.3 \\
\hline
\end{tabular}



model
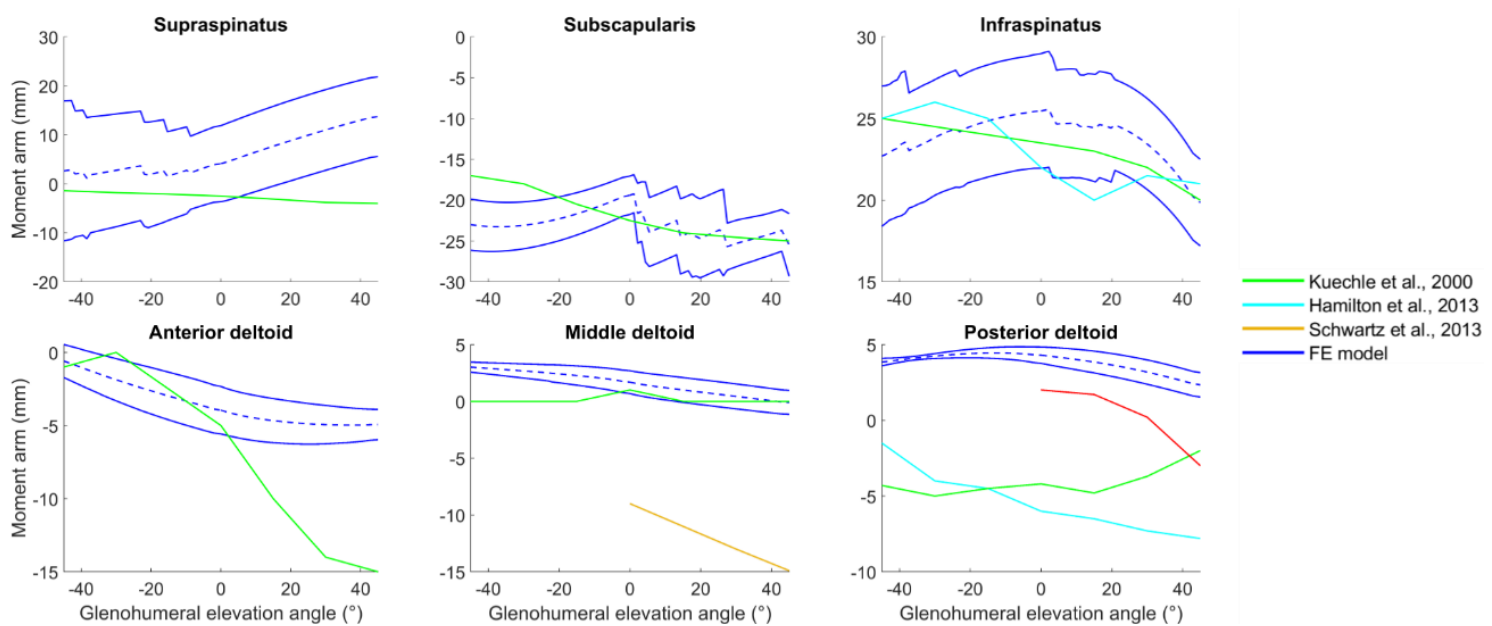

Figure 5 - Average moment arms in rotation from various studies summarized in Hik, et al. (2019) and the mean (blue dashed line) and the standard deviation (blue line) from the FE model. Discontinuities in moment arms of the supraspinatus, subscapularis and infraspinatus are due to interaction between the structures changing the point considered to compute the moment arms. Discontinuities are not due to the method of calculation of moment arms (same results were obtained with more point on the line of action). 

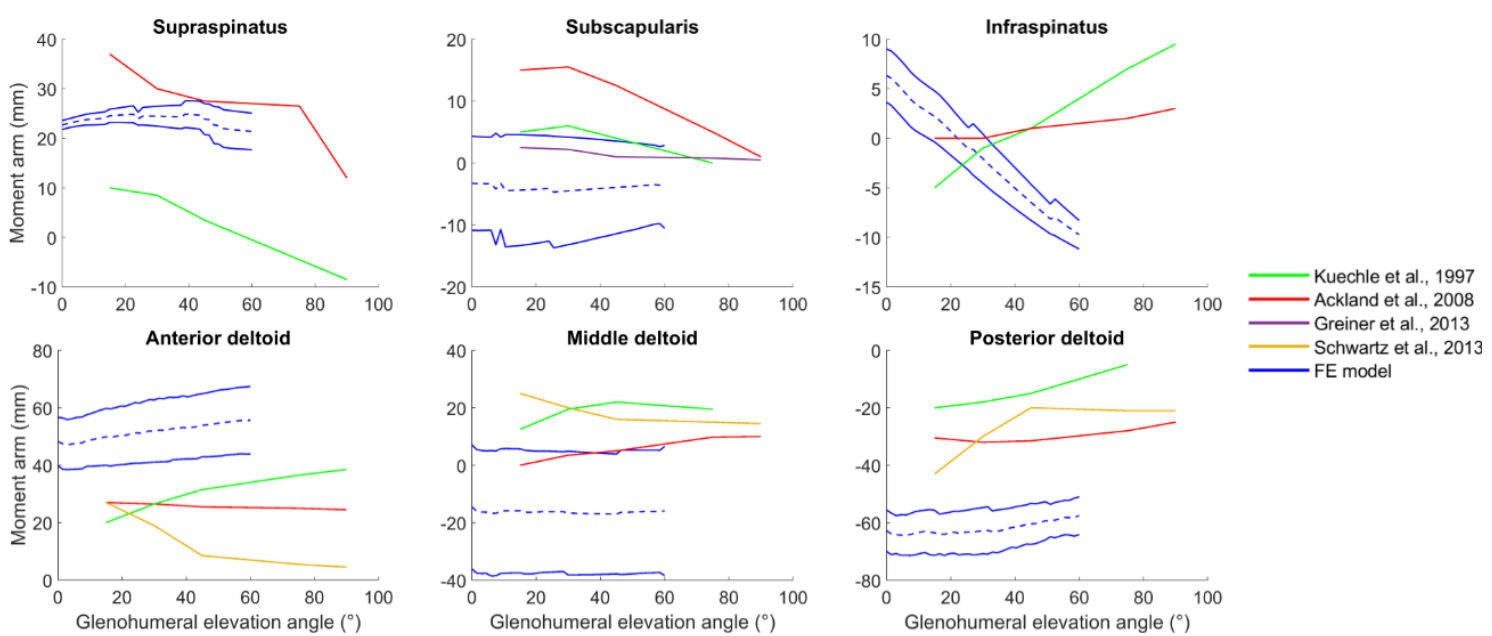

Figure 6 - Average moment arms in flexion from various studies summarized in Hik, et al. (2019) and the mean (blue dashed line) and the standard deviation (blue line) from the FE model 

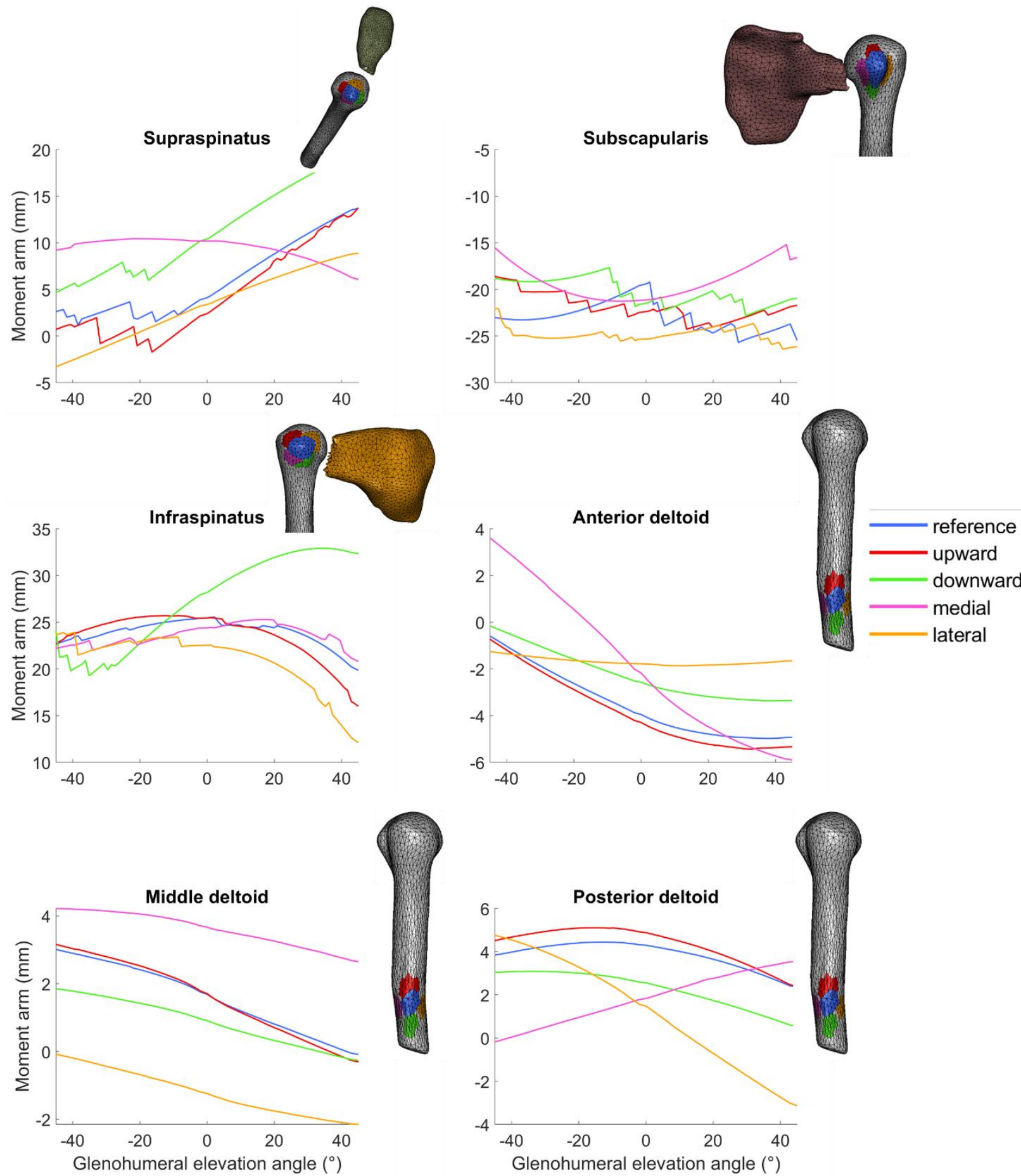

Figure 7- Mean moment arms in rotation of the six lines of action for various positions of insertion area for each muscle and the corresponding illustration of insertion area for each muscle. 


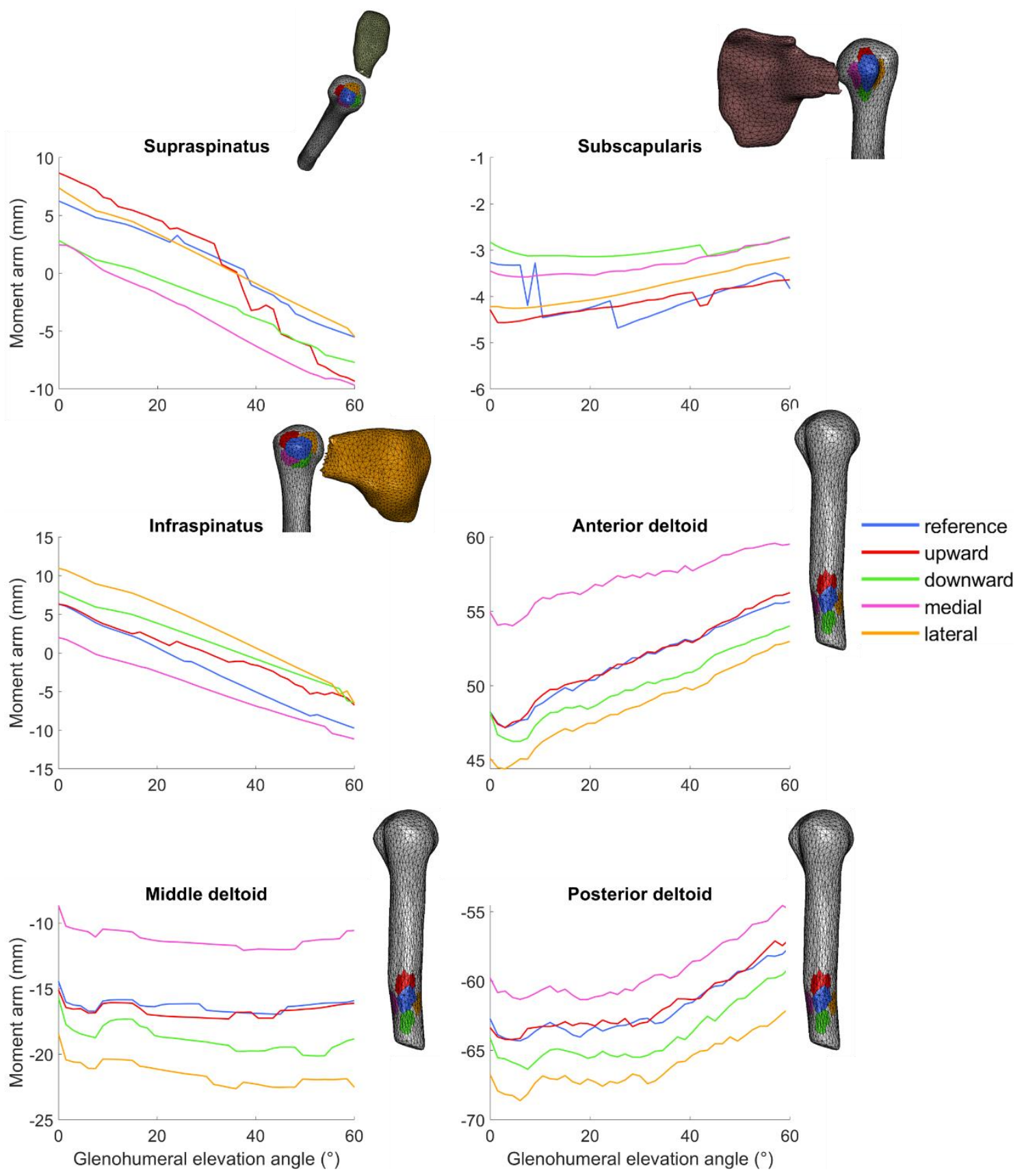

Figure 8 - Mean moment arms in flexion of the six lines of action for various positions of insertion area for each muscle and the corresponding illustration of insertion area for each muscle. 


\section{References}

Ackland DC, Pak P, Richardson M, Pandy MG. 2008. Moment arms of the muscles crossing the anatomical shoulder. J Anat.213:383-390.

Greiner S, Schmidt C, König C, Perka C, Herrmann S. 2013. Lateralized reverse shoulder arthroplasty maintains rotational function of the remaining rotator cuff. Clin Orthop Relat Res.471:940-946.

Hamilton MA, Roche CP, Diep P, Flurin P-H, Routman HD. 2013. Effect of prosthesis design on muscle length and moment arms in reverse total shoulder arthroplasty. Bull Hosp Jt Dis.71:S31-35.

Hik F, Ackland DC. 2019. The moment arms of the muscles spanning the glenohumeral joint: a systematic review. J Anat.234:1-15.

Kuechle DK, Newman SR, Itoi E, Morrey BF, An K-N. 1997. Shoulder muscle moment arms during horizontal flexion and elevation. J Shoulder Elbow Surg.6:429-439.

Kuechle DK, Newman SR, Itoi E, Niebur GL, Morrey BF, An K-N. 2000. The relevance of the moment arm of shoulder muscles with respect to axial rotation of the glenohumeral joint in four positions. Clin Biomech.15:322-329.

Schwartz DG, Kang SH, Lynch TS, Edwards S, Nuber G, Zhang L-Q, Saltzman M. 2013. The anterior deltoid's importance in reverse shoulder arthroplasty: a cadaveric biomechanical study. J Shoulder Elbow Surg.22:357-364.

\section{References}

Ackland DC, Lin Y-C, Pandy MG. 2012. Sensitivity of model predictions of muscle function to changes in moment arms and muscle-tendon properties: a Monte-Carlo analysis. J Biomech.45:1463-1471.

Ackland DC, Pak P, Richardson M, Pandy MG. 2008a. Moment arms of the muscles crossing the anatomical shoulder. Journal of Anatomy.213:383-390.

Ackland DC, Pak P, Richardson M, Pandy MG. 2008b. Moment arms of the muscles crossing the anatomical shoulder. J Anat.213:383-390.

Apreleva M, Özbaydar M, Fitzgibbons PG, Warner JJ. 2002. Rotator cuff tears: the effect of the reconstruction method on three-dimensional repair site area. Arthroscopy: The Journal of Arthroscopic \& Related Surgery.18:519-526.

Blemker SS, Delp SL. 2005. Three-dimensional representation of complex muscle architectures and geometries. Ann Biomed Eng.33:661-673.

Bolsterlee B, Zadpoor AA. 2014. Transformation methods for estimation of subjectspecific scapular muscle attachment sites. Comput Methods Biomech Biomed Engin. 17:1492-1501.

Carbone V, van der Krogt MM, Koopman HF, Verdonschot N. 2012. Sensitivity of subject-specific models to errors in musculo-skeletal geometry. J Biomech.45:24762480.

Curtis AS, Burbank KM, Tierney JJ, Scheller AD, Curran AR. 2006. The insertional footprint of the rotator cuff: an anatomic study. Arthroscopy: The Journal of Arthroscopic \& Related Surgery.22:603-609. e601.

Elwell JA, Athwal GS, Willing R. 2018. Development and validation of a muscle wrapping model applied to intact and reverse total shoulder arthroplasty shoulders. Journal of Orthopaedic Research®.36:3308-3317. 
Geuzaine C, Remacle J-F. Gmsh: a three-dimensional finite element mesh generator with built-in pre-and post-processing facilities. Proceedings of the Proceedings of the Second Workshop on Grid Generation for Numerical Computations, Tetrahedron II; 2007.

Greiner S, Schmidt C, König C, Perka C, Herrmann S. 2013. Lateralized reverse shoulder arthroplasty maintains rotational function of the remaining rotator cuff. Clin Orthop Relat Res.471:940-946.

Haering D, Raison M, Begon M. 2014. Measurement and description of threedimensional shoulder range of motion with degrees of freedom interactions. J Biomech Eng.136:084502.

Hamilton MA, Roche CP, Diep P, Flurin P-H, Routman HD. 2013. Effect of prosthesis design on muscle length and moment arms in reverse total shoulder arthroplasty. Bull Hosp Jt Dis.71:S31-35.

Herrmann S, König C, Heller M, Perka C, Greiner S. 2011a. Reverse shoulder arthroplasty leads to significant biomechanical changes in the remaining rotator cuff. Journal of orthopaedic surgery and research.6:42.

Herrmann S, König C, Heller M, Perka C, Greiner S. 2011b. Reverse shoulder arthroplasty leads to significant biomechanical changes in the remaining rotator cuff. J Ortho Surg Res.6:42.

Hik F, Ackland DC. 2019. The moment arms of the muscles spanning the glenohumeral joint: a systematic review. J Anat.234:1-15.

Hoffmann M, Begon M, Abdelnour R, Duprey S. 2019. Changes in shoulder muscle geometry at different level of isometric contracion. 44ème congrès de la Société de Biomécanique.

Hoffmann M, Haering D, Begon M. 2017a. Comparison between line and surface mesh models to represent the rotator cuff muscle geometry in musculoskeletal models. Comp Methods Biomech Biomed Eng.20:1175-1181.

Hoffmann M, Haering D, Begon M. 2017b. Comparison between line and surface mesh models to represent the rotator cuff muscle geometry in musculoskeletal models. Computer Methods in Biomechanics and Biomedical Engineering.20:1175-1181. Holzbaur KR, Murray WM, Delp SL. 2005. A model of the upper extremity for simulating musculoskeletal surgery and analyzing neuromuscular control. Ann Biomed Eng.33:829-840.

Holzbaur KR, Murray WM, Gold GE, Delp SL. 2007. Upper limb muscle volumes in adult subjects. J Biomech.40:742-749.

Hughes RE, Niebur G, Liu J, An K-N. 1997. Comparison of two methods for computing abduction moment arms of the rotator cuff. J Biomech.31:157-160.

Itoi E, Berglund LJ, Grabowski JJ, Schultz FM, Growney ES, Morrey BF, An KN. 1995. Tensile properties of the supraspinatus tendon. J Ortho Res.13:578-584. Jackson M, Michaud B, Tétreault P, Begon M. 2012. Improvements in measuring shoulder joint kinematics. J Biomech.45:2180-2183.

Jackson M, Tétreault P, Allard P, Begon M. 2013. Optimal shoulder immobilization postures following surgical repair of rotator cuff tears: a simulation analysis. J Shoulder Elbow Surg.22:1011-1018.

Kikinis R, Pieper SD, Vosburgh KG. 2014. 3D Slicer: a platform for subject-specific image analysis, visualization, and clinical support. In: Intraoperative imaging and image-guided therapy. Springer. p. 277-289.

Kim SY, Boynton EL, Ravichandiran K, Fung LY, Bleakney R, Agur AM. 2007. Three-dimensional study of the musculotendinous architecture of supraspinatus and its functional correlations. Clinical Anatomy: The Official Journal of the American 
Association of Clinical Anatomists and the British Association of Clinical Anatomists.20:648-655.

Kuechle DK, Newman SR, Itoi E, Morrey BF, An K-N. 1997a. Shoulder muscle moment arms during horizontal flexion and elevation. Journal of Shoulder and Elbow Surgery.6:429-439.

Kuechle DK, Newman SR, Itoi E, Morrey BF, An K-N. 1997b. Shoulder muscle moment arms during horizontal flexion and elevation. J Shoulder Elbow Surg.6:429439.

Kuechle DK, Newman SR, Itoi E, Niebur GL, Morrey BF, An K-N. 2000. The relevance of the moment arm of shoulder muscles with respect to axial rotation of the glenohumeral joint in four positions. Clin Biomech.15:322-329.

Leschinger T, Birgel S, Hackl M, Staat M, Müller LP, Wegmann K. 2019. A musculoskeletal shoulder simulation of moment arms and joint reaction forces after medialization of the supraspinatus footprint in rotator cuff repair. Comput Methods Biomech Biomed Engin.1-10.

Liu J, Hughes R, Smutz W, Niebur G, Nan-An K. 1997a. Roles of deltoid and rotator cuff muscles in shoulder elevation. Clinical Biomechanics.12:32-38.

Liu J, Hughes R, Smutz W, Niebur G, Nan-An K. 1997b. Roles of deltoid and rotator cuff muscles in shoulder elevation. Clin Biomech.12:32-38.

Marsden S, Swailes D, Johnson G. 2008. Algorithms for exact multi-object muscle wrapping and application to the deltoid muscle wrapping around the humerus.

Proceedings of the Institution of Mechanical Engineers, Part H: Journal of Engineering in Medicine.222:1081-1095.

Marsden SP. 2010. Muscle Wrapping Techniques Applied to the Shoulder The University of Newcastle Upon Tyne.

Mueller M, Hoy G. 2014. Soft tissue balancing in total shoulder replacement. Current reviews in musculoskeletal medicine.7:16-21.

Nagy AP, Benson DJ, Kaul V, Palmer M. 2018. Constitutive Modeling of Biological Soft Tissues.

Neri BR, Chan KW, Kwon YW. 2009. Management of massive and irreparable rotator cuff tears. J Shoulder Elbow Surg.18:808-818.

Nikooyan AA, Veeger H, Chadwick E, Praagman M, van der Helm FC. 2011.

Development of a comprehensive musculoskeletal model of the shoulder and elbow.

Medical \& biological engineering \& computing.49:1425-1435.

Quental C, Folgado J, Ambrósio J, Monteiro J. 2015. Critical analysis of

musculoskeletal modelling complexity in multibody biomechanical models of the upper limb. Comp Methods Biomech Biomed Eng.18:749-759.

Schwartz DG, Kang SH, Lynch TS, Edwards S, Nuber G, Zhang L-Q, Saltzman M. 2013a. The anterior deltoid's importance in reverse shoulder arthroplasty: a cadaveric biomechanical study. J Shoulder Elbow Surg.22:357-364.

Schwartz DG, Kang SH, Lynch TS, Edwards S, Nuber G, Zhang L-Q, Saltzman M. 2013b. The anterior deltoid's importance in reverse shoulder arthroplasty: a cadaveric biomechanical study. Journal of shoulder and elbow surgery.22:357-364.

Schwartz DG, Kang SH, Lynch TS, Edwards S, Nuber G, Zhang L-Q, Saltzman MJJoS, Surgery E. 2013. The anterior deltoid's importance in reverse shoulder arthroplasty: a cadaveric biomechanical study.22:357-364.

Seg3D C. 2013. Volumetric image segmentation and visualization. Scientific

Computing and Imaging Institute (SCI).

Stelletta J, Dumas R, Lafon Y. 2016. In Biomechanics of Living Organs: Hyperelastic Constitutive Laws for Finite Element Modeling. Elsevier.497-521. 
Walker DR, Struk AM, Matsuki K, Wright TW, Banks SA. 2016. How do deltoid muscle moment arms change after reverse total shoulder arthroplasty? J Shoulder Elbow Surg.25:581-588.

Walker DR, Struk AM, Matsuki K, Wright TW, Banks SAJJoS, Surgery E. 2016. How do deltoid muscle moment arms change after reverse total shoulder arthroplasty? ;25:581-588.

Webb JD, Blemker SS, Delp SL. 2014. 3D finite element models of shoulder muscles for computing lines of actions and moment arms. Comp Methods Biomech Biomed Eng.17:829-837.

Wu G, Van der Helm FC, Veeger HD, Makhsous M, Van Roy P, Anglin C, Nagels J, Karduna AR, McQuade K, Wang X. 2005. ISB recommendation on definitions of joint coordinate systems of various joints for the reporting of human joint motion-Part II: shoulder, elbow, wrist and hand. J Biomech.38:981-992.

Yamamoto N, Itoi E, Tuoheti Y, Seki N, Abe H, Minagawa H, Shimada Y, Okada K. 2007. Glenohumeral joint motion after medial shift of the attachment site of the supraspinatus tendon: a cadaveric study. J Shoulder Elbow Surg.16:373-378.

Zheng M, Qian Z, Zou Z, Peach C, Ren L. 2019. Subject-specific Finite Element Modelling of the Human Shoulder Complex Part2: Quantitative Evaluation of the Effect of Rotator Cuff Tear Propagation on Glenohumeral Joint Stability. IEEE Access. Zheng M, Zou Z, Bartolo PJDS, Peach C, Ren L. 2017. Finite element models of the human shoulder complex: a review of their clinical implications and modelling techniques. Int J Numer Meth Eng.33:e02777. 